\title{
The efficacy of the electric patient hoist systems in mobilization
}

\author{
D Tomris Duymaz, ${ }^{1}$ (D) Levent Ozgonenel, ${ }^{2}$ (D) Zeynep Erdogan Iyigun ${ }^{2}$ \\ ${ }^{1}$ Department of Physiotherapy and Rehabilitation, Istanbul Bilgi University Faculty of Health Science, Istanbul, Turkey \\ 2Department of Physical Therapy and Rehabilitation, Istanbul Bilim University Faculty of Medicine, Istanbul, Turkey
}

\begin{abstract}
OBJECTIVE: Long-term immobilization brings about physiological and biomechanical adverse effects on organs and systems. For enabling patients to stand on their feet and to be mobilized in the early period, electric patient hoist system (EPHS) accelerates the recovery of systemic functions and allows the patient with neurological diseases to become independent. This study aimed to investigate whether EPHS differs from conventional systems in the duration of hospitalization, mobility level and return to activities of daily living by analyzing patients mobilized with EPHS in the early period.

METHODS: We analyzed 30 patients with neurological diseases, who were aged 50-75 years and immobile for more than one week. The patients were divided into two groups as EPHS patients and controls. Before and after the treatment, we recorded age, height, weight, hospitalization duration and time of mobilization. Mobility was assessed using the clinical and Rivermead mobility indexes while daily activities were evaluated with the Barthel index.

RESULTS: Our results indicated that the hospitalization duration decreased significantly in the patients practicing with EPHS in comparison with the controls $(p=0.014)$. When the groups were compared regarding the pre- and post-treatment outcomes of the clinical and Rivermead mobility indexes, the mobility levels of the EPHS group showed more considerable improvement $(p<0.001)$. The Barthel index demonstrated that the EPHS patients showed significantly higher participation in daily life within a significantly shorter time $(p=0.002)$.

CONCLUSION: Applying EPHS in the early period of hospitalization extends the time patients stand on their feet, enabling them to spend this time effectively. In conclusion, intervening immobile patients with EPHS in addition to their early rehabilitation program achieved earlier mobilization, shorter hospitalization and easier return to daily life activities.
\end{abstract}

Keywords: Electric patient hoist system; immobilization; neurological diseases.

Cite this article as: Duymaz T, Ozgonenel L, Erdogan Iyigun Z. The efficacy of the electric patient hoist systems in mobilization. North Clin Istanb 2019;6(4):361-367.

$\mathrm{T}$ he majority of the patients receiving inpatient treatment suffers from the restriction of movements due to poor overall health status, pain, or disorders in the musculoskeletal system. This condition, which is known as immobilization, leads to a decrease in patients' muscle strength and aerobic capacity within a short period ( 1 to 2 weeks). Prolonged hospitalization also may cause various problems, including the limitation of joint mobility, loss of function, increase in infections, osteoporosis, loss of deep sensation, bedsores and respiratory problems in addition to the problems reported above $[1,2]$. There are several studies reporting that long-term immobilization immediately brings about physiological and biomechanical negative effects on organs and systems. Geriatric patients are particularly at risk of immobilization-related problems [3]. The loss of mobilization increases the risk 
of disability, morbidity, prolonged hospitalization, and increased healthcare expenses and death. Approximately $50 \%$ of the patients over the age of 70 years lose their ability to walk, and $30 \%$ have difficulty in bathing. Especially difficulty in the activity of bathing is one of the determining factors of long-term patient care. Previous studies indicated that patients started to be mobilized at an early period could regain walking ability more quickly and return to the activities of daily life more easily with decreased complications [4-7].

Practicing with an electric patient hoist system accelerates the process to regain walking ability which improves patients' quality of life and positively affects their psychological state [8]. Early mobilization improves neurological balance, coordination and physiological, emotional and cognitive states. Moreover, it enhances cardiopulmonary factors, including pulse rate, blood pressure, aerobic capacity and aerobic endurance. Regarding the orthopedic factors, early mobilization enables the prevention of musculoskeletal injuries, muscle atrophy, development of osteoporosis, and deep sensory impairment. Considering the financial benefits, early mobilization shortens the duration of hospitalization, and thus, contributes to both individual and social-economic development by decreasing hospital costs, home care costs, and the need for the purchase of additional immobilization-related devices [9].

Studies in the literature give wide publicity to assistive ambulation devices, but patients have some problems in using such devices while walking. Walking with an assistive device elevates the energy patients spend for walking and increases the risk of falling and getting injured. Despite the satisfaction of being able to walk, the patients cannot get rid of the depressing feeling of dependence [10]. On the other side, using patient handling systems for mobilization as of the early stages of hospitalization can help to reduce musculoskeletal system atrophy, deep sensory loss, and visible bedsores in the future while reducing the duration of hospitalization and enable patients to walk more independently after discharge. With the electric patient hoist systems, it is possible to support patients mechanically and have them to stand on their feet safely even if they do not have enough strength to stand.

There are studies in the literature addressing the use of patient transfer devices and tilt table; however, we did not come across any study on the use of electric patient hoist systems that we employed in our study $[7,8]$. Therefore, this study can be considered as the first study on the electric patient hoist systems. This study aims to investigate whether electric patient hoist systems differ from conventional systems in hospitalization, mobility level and return to activities of daily living by analyzing patients mobilized with electric patient hoist in the early period.

\section{MATERIALS AND METHODS}

We analyzed 30 patients who were aged $50-75$ years and immobile for more than one week. This study was approved by Istanbul Bilgi University Committee on Ethics in Research on Humans. Patients who underwent a surgical procedure causing immobilization and patients with a disease affecting the condition of the musculoskeletal system were included in this study. The exclusion criteria included any impairment in cooperation, orientation and cognitive status. The patients were divided into two groups as follows: patients receiving rehabilitation and patients intervened with James electric patient hoist system in addition to rehabilitation (Fig. 1).

As a result of the power analysis performed, it was calculated that $80 \%$ of the power would be obtained for the $95 \%$ confidence interval when 30 patients were accepted in this study.

Randomisation: Patients who met the study criteria were randomized according to treatment order.

All patients received 15 sessions of therapy. Patients' data, including age, height, weight, hospitalization duration and time of mobilization, were recorded both before and after the treatment. Mobility was assessed using the clinical and Rivermead mobility indexes while daily activities were evaluated with the Barthel index.

The Rivermead Mobility Index (RMI) is a onedimensional index that focuses on the mobility level and contains basic mobility activities. RMI consists of 14-self-reported items and one direct observation item fulfilling the Guttman scaling criteria and covers several hierarchical activities ranging from turning in bed to running. RMI was primarily developed to measure the outcomes of physiotherapy interventions after head trauma or stroke and reported to be confidently used at hospitals, polyclinics, or home environment without the requirement of a specific specialty. The answers to the questions were based on the statements of the patients. Only the $5^{\text {th }}$ item was evaluated according to the observations of the interviewer. Each item receives a score of 0 for "No" response and 1 for "Yes" response, and the total score may 


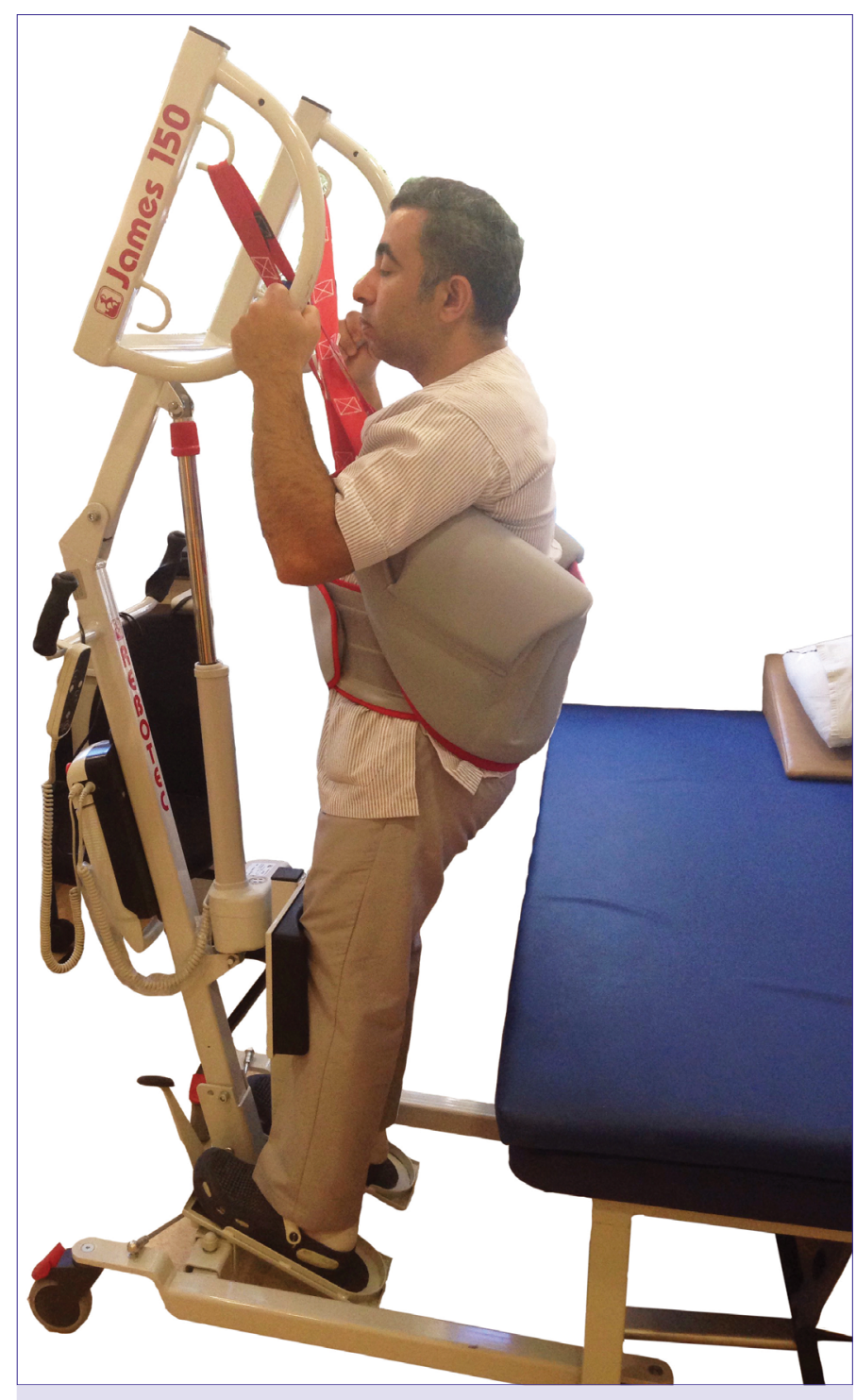

FIGURE 1. Application of James lift system.

be between $0-15$ points. The highest score, which is 15 points, shows that there is no mobility problem while the scores $\leq 14$ points refers to problems in mobility.

The clinical mobility scale assesses a patient's degree of mobility through specific parameters, including upright posture, walking, gait, sitting, stair climbing, hand-held appliances, wheelchair, and time usage. These parameters are evaluated through questions rated $0-3$ points. The total score can range from 0 to 24 . Higher scores indicate better mobility [11].

The Barthel index assesses the activities of daily living under the sub-titles of feeding, transfer, grooming, bathing, walking, and toilet use, wheelchair use, climbing stairs, dressing, bowel care and bladder care. Each item can be given as 0,5 and 10 points. Considering the total

\section{TABLE 1. Demographic characteristics of the patients}

\begin{tabular}{lcccc} 
& $\begin{array}{c}\text { James } \\
\text { group } \\
(\mathrm{n}=15) \\
\text { Mean } \pm \mathrm{SD}\end{array}$ & $\begin{array}{c}\text { Control } \\
\text { group } \\
(\mathrm{n}=15) \\
\text { Mean } \pm S \mathrm{SD}\end{array}$ & $\mathrm{z}$ & $\mathrm{p}$ \\
& & & \\
\hline Age $($ year $)$ & $63.00 \pm 7.37$ & $65.40 \pm 10.02$ & -0.598 & $0.550^{\mathrm{m}}$ \\
BMI $\left(\mathrm{kg} / \mathrm{m}^{2}\right)$ & $25.10 \pm 1.09$ & $26.55 \pm 4.16$ & -0.759 & $0.448^{\mathrm{m}}$ \\
\hline
\end{tabular}

SD: Standard deviation; m: Mann-Whitney U Test; BMI: Body mass index.

score a patient can achieve, the scores of 0-20 indicate "total" dependency; 21-60 indicate "severe" dependency; 61-90 indicate "moderate" dependency, and 91-99 indicates "slight" dependency while a score of 100 indicates "total independency" [11].

\section{Statistical analysis}

All analyses were performed with the SPSS (version 22.0) statistical package program. Descriptive statistics are given as mean, standard deviation, median for numerical variables, number and percentage for categorical variables. Mann-Whitney $U$ test was employed to compare outcome scores among treatment groups compared since the numerical variables did not make the normal distribution condition. Numerical variables in dependent groups were compared using Spearman's correlation test in multiple groups, and subgroup analyses were performed using Wilcoxon tests. Statistical significance was considered at 0.05 .

\section{RESULTS}

The groups were homogeneous regarding patients' age and BMI (Table 1). The duration of hospitalization was significantly shorter in the group mobilized using the electric patient hoist systems as compared to the controls $(p=0.014)$ (Table 2). When the groups were compared regarding the pre- and post-treatment outcomes of the clinical and Rivermead mobility indexes, the mobility levels of the EPHS group showed a greater improvement $(p<0.001)$. The outcomes of the Barthel index demonstrated that the patients practicing with the electric patient hoist system showed significantly higher participation in daily life within a significantly shorter time $(p=0.002)$ (Table 2). 
TABLE2. Comparison of intergroup and in-group hospital stay, mobility indexes and Barthel index

\begin{tabular}{|c|c|c|c|c|}
\hline Duration of the hospitalization & $2.66 \pm 0.98$ & $6.20 \pm 4.26$ & -2.463 & $0.014^{m}$ \\
\hline \multicolumn{5}{|l|}{ Clinical Mobility Index } \\
\hline Pre-treatment & $1.08 \pm 1.62$ & $2.00 \pm 3.43$ & -0.222 & $0.824^{\mathrm{m}}$ \\
\hline Post-treatment & $12.83 \pm 5.76$ & $2.60 \pm 3.40$ & -3.478 & $<0.001^{m}$ \\
\hline \multicolumn{5}{|l|}{ Rivermead Mobility Index } \\
\hline Pre-treatment & $0.66 \pm 0.88$ & $2.20 \pm 3.08$ & -1.349 & $0.177^{\mathrm{m}}$ \\
\hline Post-treatment & $7.58 \pm 2.81$ & $2.50 \pm 3.06$ & -3.250 & $<0.001^{m}$ \\
\hline z & -3.063 & -1.732 & & \\
\hline $\mathrm{p}$ & $0.002^{w}$ & $0.083^{w}$ & & \\
\hline z & -3.066 & -1.414 & & \\
\hline $\mathrm{p}$ & $0.002^{w}$ & $0.157^{w}$ & & \\
\hline
\end{tabular}

SD: Standard deviation; m: Mann-Whitney U Test ; w: Wilcoxon Test.

TABLE 3. Correlation of hospitalization duration with mobility and daily living activity scores

$\begin{array}{ll}\text { Groups } & \begin{array}{l}\text { Duration of the } \\ \text { hospitalization }\end{array}\end{array}$

James group

Clinical Mobility Index $r$

$\mathrm{p}$

Rivermead Mobility Index

$r$

$p$

Barthel Index

$r$

$p$

Control group

Clinical Mobility Index

$r$

$\mathrm{p}$

Rivermead Mobility Index

$r$

$\mathrm{p}$

Barthel Index

$r$

$\mathrm{p}$

Spearman's Correlation Test.
Although the correlation analysis showed a negative correlation between the patients' hospitalization duration and their mobility levels and daily living activities in both groups, this correlation was not statistically significant $(\mathrm{p}>0.05)$ (Table 3).

\section{DISCUSSION}

$-.410$

0.186

$-.011$

0.972

$-.216$

0.501

$-.311$

0.381

$-.613$

0.060

$-.315$

0.375

The common aim of physiotherapy techniques implemented within the scope of early rehabilitation programs for patients who have prolonged bed rest due to chronic illnesses is to ensure mobility, positioning, and standing of the patient $[12,13]$.

As a result of this study, we observed that when the patients, who were immobile for more than one week, were intervened with an electric patient hoist system in addition to their early rehabilitation program, they could be mobilized earlier and have shorter hospitalization and easier return to daily life activities.

The purpose of rehabilitation in the cases of prolonged immobilization after a sudden illness is to transfer and mobilize the patient as soon as possible. Skeletal muscle strength declines by $1 \%$ to $1.5 \%$ per day of strict bed rest and by $4 \%$ to $5 \%$ for each week of bed rest which causes $10 \%$ loss in postural muscle strength after 
one week. Especially elderly patients are more likely to have difficulty in mobilization because their independent walking desire is further reduced [14-17]. A study in the relevant literature reported that when bed rest continues for more than one week, the risk of polyneuropathy as well as muscle atrophy increases by $84 \%$ [18].

Elliot et al. and Wilson et al. [19, 20] suggested that early mobilization therapy precipitates the mobilization process (the time to the first mobilization). In parallel to the information given above, we started mobilization exercises for the patients receiving therapy with the electric patients' hoist system on the $3^{\text {rd }}$ day of hospitalization on average and observed that their mobility capability enhanced.

Verticalization stimulates the corresponding areas in the cortical region, which control the body and lower extremity, and thus, protects muscle strength, function, and core stabilization $[13,21]$. Acceleration of blood flow in the cerebral region also improves cognitive function by stimulating cortical plasticity, particularly in the frontal lobe [22]. Another benefit is to provide voluntary movement and body stabilization during and after standing by getting involved in the healing of the vestibular system [23]. Plasticization in the vestibular system provides further stabilization of the vertical position, reduces the risk of falling while enabling the regain of postural reflexes and sensory-motor system functions [24, 25].

The electric patient hoist system is a system that allows patients with strict bed rest to move to the vertical position earlier and be mobilized safely. An early rehabilitation program, which involves having patients to stand on their feet as soon as possible, aims to promote functional recovery in patients with chronic illnesses. Using the James device-one of the electric patient hoist systems- makes it possible to support patients mechanically and have them to stand on their feet safely even if they do not have enough strength to stand up. In this way, potential complications related to extended immobilization, such as muscle atrophy, joint contractures, peripheral nerve injuries, osteoporosis, renal dysfunctions, orthostatic hypotension, decreased oxygen consumption, venous ponding, decreased lung capacity and respiratory dysfunction and bedsores, can be prevented [25].

Chang et al. reported that keeping patients on their feet in the early period of hospitalization made $63.8 \%$ improvement in joint's range of motion, $58.6 \%$ improvement in muscle strength and $62.1 \%$ improvement in the cognitive level. Although the improvement in the venti- lation of lungs was not as significant as the improvement in the musculoskeletal system, it was demonstrated that having patients to stand on their feet for five minutes increased the rate of ventilation per minute. In conclusion, only standing on the feet even has a healing effect on the musculoskeletal system and respiratory functions and the implementation of additional devices promotes such healing [26].

Patients who have long-term bed rest must be mobilized to perform their physical and physiological functions and participate in the activities of daily living. Although mobilization can be provided partially using transfer devices or with manual help, these methods have some negative aspects. Patients can be transferred from bed to wheelchair, restroom or bathroom and vice versa using mechanical transfer devices; however, such mobilization is limited, and also permanent use of the mechanical transfer devices is costly and these devices are nor ergonomic as they occupy large areas in the house. Additionally, the mobilization of patients with manual help poses a high risk for injury both for patients and helpers. Electric patient hoist systems have the lowest risk of injuries since they load an extra burden on neither the patient nor the healthcare worker while mobilizing the patients that have been immobilized for a long time. Therefore, these systems can be safely used [27]. Horodydki et al. conducted a study on patients with spinal cord injuries and reported that using mechanical handling devices is safer than mobilizing patients manually [28].

During transfer or manual mobilization procedures, patients are particularly at increased risk of pain in the upper extremities, injuries in the lower limbs, and traumas such as crush and falling as well as fractures due to such traumas. Moreover, the risk of injury, back pain, and lumbar pain is high among the healthcare workers who help mobilization as physical stress is applied on the joints while trying to carry the weight of the patient [29]. On the other side, electric patient hoist systems allow the healthcare worker to easily adjust the device to suit his needs and to keep the patient standing on the feet without any extra effort $[30,31]$.

Riberholt et al. [32] stated that having patients to step on the ground as of an early period activates the proprioceptors on the bottom of the feet, allowing patients to be mobilized more quickly and accelerating their return to daily activities of living. McWilliams et al. [33] divided sixty-three intensive care patients into two groups and subjected them to rehabilitation. They used an extra de- 
vice for practicing sitting and standing positions, respectively for one of the groups. As a result of their study, they observed that the time to the first mobilization was shorter in the patients practicing with the device, and these patients could be discharged from the hospital earlier, and they could return to their activities of daily life within a shorter time according to the Barthel index.

Consistent with the literature, we found that the hospitalization period of the patients who practiced standing with the James electric patient hoist system showed a decrease and our Barthel index outcomes indicated that these patients could return to the daily activities of living more quickly.

This study has some limitations which should be pointed out. First, we did not make a comparison between different handling systems. Second, we recorded only patients' mobility levels but not their muscle strength and respiratory functions. The third limitation is that the patients were not classified by the diagnoses, but all immobilized patients should be evaluated together.

In conclusion, intervening immobile patients with electric patient hoist systems in addition to their early rehabilitation program achieved earlier mobilization, shorter hospitalization and higher participation in the activities of daily living.

Ethics Committee Approval: This study was approved by Istanbul Bilgi University Committee on Ethics in Research on Humans (201840016-46/24.04.2018).

Conflict of Interest: The authors declare no conflict of interest.

Financial Disclosure: The authors declared that this study has received no financial support.

Authorship Contributions: Concept - TD, LO; Design - LO, ZEI; Supervision - LO; Materials - TD, LO; Data collection and/or processing - TD; Analysis and/or interpretation - TD, LO, ZEI; Writing - TD, LO; Critical review - LO, ZEI.

\section{REFERENCES}

1. Czell D, Schreier R, Rupp R, Eberhard S, Colombo G, Dietz V. Influence of passive leg movements on blood circulation on the tilt table in healthy adults. J Neuroeng Rehabil 2004;1:4. [CrossRef]

2. Dietz V, Müller R, Colombo G. Locomotor activity in spinal man: significance of afferent input from joint and load receptors. Brain 2002;125:2626-34. [CrossRef]

3. Gill TM, Gahbauer EA, Murphy TE, Han L, Allore HG. Risk factors and precipitants of long-term disability in community mobility: a cohort study of older persons. Ann Intern Med 2012;156:131-40.

4. Hardy SE, Kang Y, Studenski SA, Degenholtz HB. Ability to walk $1 / 4$ mile predicts subsequent disability, mortality, and health care costs. J Gen Intern Med 2011;26:130-5. [CrossRef]
5. Newman AB, Simonsick EM, Naydeck BL, Boudreau RM, Kritchevsky $\mathrm{SB}, \mathrm{Nevitt} \mathrm{MC}$, et al. Association of long-distance corridor walk performance with mortality, cardiovascular disease, mobility limitation, and disability. JAMA 2006;295:2018-26. [CrossRef]

6. Gill TM, Han L, Allore HG. Predisposing factors and precipitants for bathing disability in older persons. J Am Geriatr Soc 2007;55:534-40.

7. Greer N, Brasure M, Wilt TJ. Wheeled mobility (wheelchair) service delivery: scope of the evidence. Ann Intern Med 2012;156:141-6.

8. Jackson AB, Carnel CT, Ditunno JF, Read MS, Boninger ML, Schmeler $\mathrm{MR}$, et al. Outcome measures for gait and ambulation in the spinal cord injury population. J Spinal Cord Med 2008;31:487-99. [CrossRef]

9. Mathieson KM, Kronenfeld JJ, Keith VM. Maintaining functional independence in elderly adults: the roles of health status and financial resources in predicting home modifications and use of mobility equipment. Gerontologist 2002;42:24-31. [CrossRef]

10. Krause JS, Carter RE, Brotherton S. Association of mode of locomotion and independence in locomotion with long-term outcomes after spinal cord injury. J Spinal Cord Med 2009;32:237-48. [CrossRef]

11. Baer GD, Salisbury LG, Smith MT, Pitman J, Dennis M. Treadmill training to improve mobility for people with sub-acute stroke: a phase II feasibility randomized controlled trial. Clin Rehabil 2018;32: 20112. [CrossRef]

12. Miranda Rocha AR, Martinez BP, Maldaner da Silva VZ, Forgiarini Junior LA. Early mobilization: Why, what for and how? Med Intensiva 2017;41:429-36. [CrossRef]

13. Olkowski BF, Shah SO. Early Mobilization in the Neuro-ICU: How Far Can We Go? Neurocrit Care 2017;27:141-50. [CrossRef]

14. De Jonghe B, Sharshar T, Lefaucheur JP, Authier FJ, Durand-Zaleski I, Boussarsar M, et al. Paresis acquired in the intensive care unit: a prospective multicenter study. JAMA 2002;288:2859-67. [CrossRef]

15. Topp R, Ditmyer M, King K, Doherty K, Hornyak J 3rd. The effect of bed rest and potential of prehabilitation on patients in the intensive care unit. AACN Clin Issues 2002;13:263-76. [CrossRef]

16. Brown CJ, Ridden DT, Flood KL, Allamn RM. Underrecognized epidemic of low mobility during hospitalization of older adults. J Am Geriatr Soc 2009;57:1660-5. [CrossRef]

17. Waters TR. When is it safe to manually lift a patient? Am J Nurs 2007;107:53-8. [CrossRef]

18. Thomas DC, Kreizman IJ, Melchiorre P, Ragnarsson KT. Rehabilitation of the patient with chronic critical illness. Crit Care Clin 2002;18:695-715. [CrossRef]

19. Elliot L, Coleman M, Shiel A, Wilson BA, Badwan D, Menon D, et al. Effect of posture on levels of arousal and awareness in vegetative and minimally conscious state patients: a preliminary investigation. J Neurol Neurosurg Psych 2005;76:298-9. [CrossRef]

20. Wilson BA, Dhamapurkar S, Tunnard C, Watson P, Florschutz G. The effect of positioning on the level of arousal and awareness in patients in the vegetative state or the minimally conscious state: a replication and extension of the previous findings. Brain 2013;14:475-9. [CrossRef]

21. Pittaccio S, Zappasodi F, Tamburro G, Viscuso S, Marzetti L, Garavaglia $\mathrm{L}$, et al. Passive ankle dorsiflexion by an automated device and the reactivity of the motor cortical network. Conf Proc IEEE Eng Med Biol Soc 2013;2013:6353-6. [CrossRef]

22. Sawaki L, Butler AJ, Leng X, Wassenaar PA, Mohammad YM, Blanton $\mathrm{S}$, et al. Constraint-induced movement therapy results in increased motor map area in subjects 3 to 9 months after stroke. Neurorehabil Neural Repair 2008;22:505-13. [CrossRef]

23. Cullen KE, Roy JE. Signal processing in the vestibular system during active versus passive head movements. J Neurophysiol 2004;91:191933. [CrossRef] 
24. Andersson G, Hagman J, Talianzadeh R, Svedberg A, Larsen HC. Dual-task study of cognitive and postural interference in patients with vestibular disorders. Otol Neurotol 2003;24:289-93. [CrossRef]

25. Yardley L, Gardner M, Bronstein A, Davies R, Buckwell D, Luxon L. Interference between postural control and mental task performance in patients with vestibular disorder and healthy controls. JNNP 2001;71:48-52. [CrossRef]

26. Chang AT, Boots R, Hodges PW, Paratz J. Standing with assistance of a tilt table in intensive care: a survey of Australian physiotherapy practice. Aust J Physiother 2004;50:51-4. [CrossRef]

27. Sommers J, Wieferink DC, Dongelmans DA, Nollet F, Engelbert $\mathrm{RHH}$, van der Schaaf M. Body weight-supported bedside treadmill training facilitates ambulation in ICU patients: An interventional proof of concept study. J Crit Care 2017;41:150-5. [CrossRef]

28. Horodyski M, Weight M, Conrad B, Bearden B, Kimball J, Rechtine G. Motion generated in the unstable lumbar spine during hospital bed transfers. J Spinal Disord Tech 2009;22:45-8. [CrossRef]
29. Goh CH, Muslimah Y, Ng SC, Subramanian P, Tan MP. The Use of the Self-Standing Turning Transfer Device to Perform Bed-To-Chair Transfers Reduces Physical Stress among Caregivers of Older Patients in a Middle-Income Developing Country. Front Med (Lausanne) 2014;1:32. [CrossRef]

30. Tomioka K, Sakae K, Yasuda J. Low back load reduction using mechanical lift during transfer of patients. Sangyo Eiseigaku Zasshi 2008;50:103-10. [CrossRef]

31. Wang H, Tsai CY, Jeannis H, Chung CS, Kelleher A, Grindle GG, Cooper RA.Stability analysis of electrical powered wheelchair-mounted robotic-assisted transfer device. J Rehabil Res Dev 2014;51:761-74.

32. Riberholt CG, Thorlund JB, Mehlsen J, Nordenbo AM. Patients with severe acquired brain injury show increased arousal in tilt-table training. Dan Med J 2013;60:A4739.

33. McWilliams D, Atkins G, Hodson J, Snelson C. The Sara Combilizer as an early mobilisation aid for critically ill patients: A prospective before and after study. Aust Crit Care 2017;30:189-95. [CrossRef] 